\title{
A new laboratory device for study of subglacial processes: first results on ice-bed separation during sliding
}

\author{
Neal R. IVERSON, Ben B. PETERSEN \\ Department of Geological and Atmospheric Sciences, lowa State University, Ames, lowa 50011, USA \\ E-mail: niverson@iastate.edu
}

\begin{abstract}
A new ring-shear device allows basal slip and related processes to be studied in laboratory experiments for the cases of hard or soft beds. The device rotates a confined ring of ice $(0.9 \mathrm{~m}$ outside diameter) across a horizontal bed at a constant velocity or drag, while a vertical stress is applied and basal water pressure is controlled. A bath with circulating fluid regulated to $\sim 0.01^{\circ} \mathrm{C}$ surrounds the ice chamber and keeps the ice at its pressure-melting temperature. In a first experiment with a stepped rigid bed and zero basal water pressure, steady lengths of step cavities depended upon slip velocity raised to a power of 0.59 , in general agreement with the square-root dependence of some models of sliding and linked-cavity hydraulics. Transient cavity growth after slip velocity increases was not monotonic, with damped volume oscillations that converged to a steady value. Once ice separated from lee surfaces, drag on the bed was constant and independent of slip velocity and cavity size, consistent with a shearstress upper bound like that indicated by sliding models. Shear strains near the bed exceeded 30 and ice developed multiple-cluster $c$-axis fabrics similar to those of sheared ice in temperate glaciers.
\end{abstract}

\section{INTRODUCTION}

Processes at glacier beds have far-reaching effects (Clarke, 2005). Ice slips, enabling fast glacier flow that can trigger global environmental change (Clark and others, 1999). Ice melts, enhancing slip and sometimes depositing vast basal till sheets (e.g. Dreimanis and Gibbard, 2005). Water freezes, entraining unlithified sediment (e.g. Rempel, 2008) and reducing the supply of water that may help sustain rapid slip (e.g. Tulaczyk and others, 2000). Debris within ice scrapes against the bed, not only eroding it but inhibiting slip (e.g. Hallet, 1981). Subglacial sediment layers shear, causing high sediment fluxes, erosion or aggradation of the bed and conspicuous landforms (e.g. Boulton, 1996). Bedrock erodes, resulting in Alpine landscapes and modulating uplift in orogenic belts (e.g. Egholm and others, 2009).

Field observations used to motivate and test models of these processes have some well-known limitations. The limited spatial extent of most direct measurements beneath modern glaciers - made in boreholes, tunnels or natural cavities - causes interpretive ambiguity, as do bed control variables that change spatially and simultaneously so that isolating their effects is difficult. Remote geophysical techniques cannot adequately resolve small-scale processes and even at larger scales invariably provide incomplete characterizations. Conclusions drawn exclusively from sediments or landforms usually require subjective interpretation because information stored in the geologic record is inherently incomplete and non-unique. A result of these problems is that hypotheses are seldom rejected definitively. By the same token, hypotheses that may be close to correct commonly do not receive the definitive testing they deserve.

To consider a different approach, compare study of basal slip of glaciers with that of slip along faults in Earth's crust, which in some ways is better understood. A rate- and statedependent friction rule for fault slip is widely accepted in the fault-mechanics community (Scholz, 2002) and is used routinely in efforts to model fault-slip dynamics (e.g. Segall and others, 2010). This rule did not result from inferences made from faults exposed in the geologic record or from monitoring of fault slip in the field. Nor was this rule adopted primarily due to compelling theoretical arguments. Rather it emerged from multiple long-term efforts to study fault slip in well-controlled laboratory experiments (e.g. Dieterich, 1979; Marone, 1998).

In contrast, slip of glaciers has received meager experimental study: we are aware of no papers in over 25 years that have featured laboratory experiments in which ice was slid over either a rough rigid bed or a deformable bed. This methodological void is unnecessary. The inaccessibility of glacier beds makes them obvious candidates for study in the laboratory, and difficulties attaining subglacial stresses and temperatures are minimal. Moreover, many subglacial processes are sufficiently rapid that their rates can be reproduced in the laboratory - unlike for example those of slower processes studied in some other disciplines, such as petrology and rock physics, which are paradoxically richer in laboratory experimentation.

Thus, to complement field and theoretical studies, we have designed, constructed and begun to use a new ringshear device for the study of subglacial processes relevant to both hard and soft beds. The goal herein is to describe the device in detail and present data from an initial experiment in which temperate ice was slid across a rigid stepped bed. The results provide a means of testing, for the first time, models of ice-bed separation used in theoretical treatments of subglacial hydrology (Walder, 1986; Schoof, 2010), sliding (Humphrey, 1987; Kamb, 1987) and bedrock quarrying (Hallet, 1996).

\section{DEVICE}

Efforts to study subglacial processes in laboratory experiments with sliding ice have been relatively narrowly focused (e.g. Brepson, 1979; Budd and others, 1979; Meyssonnier, 1983; Hooke and Iverson, 1985; Iverson, 1993). The design and function of the new device are more ambitious, with the goal of allowing a wider range of subglacial processes to be studied. The following capabilities were sought: use of hard 


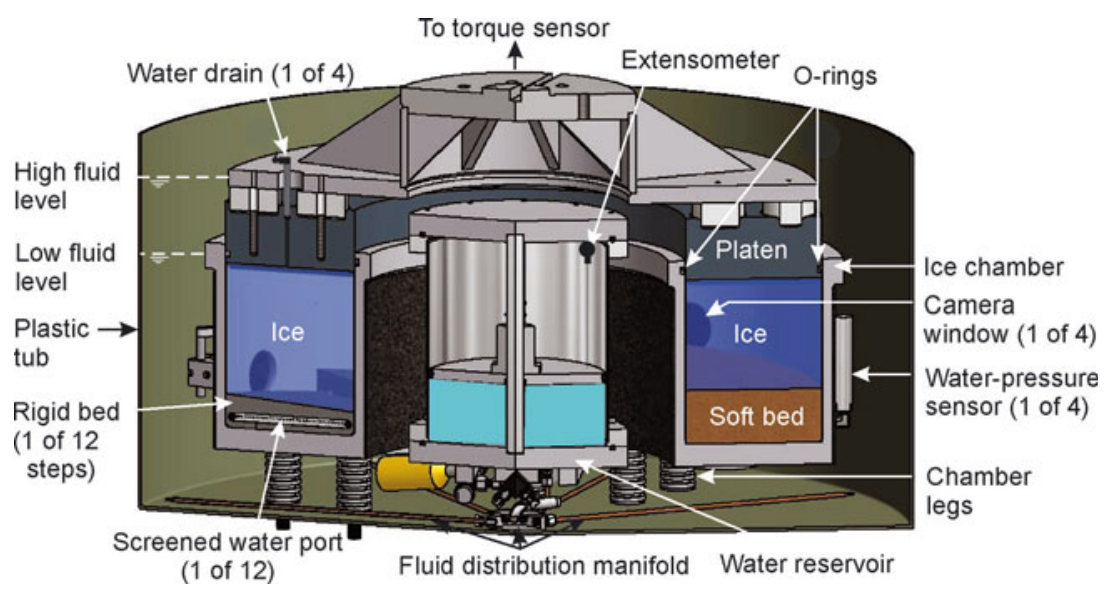

Fig. 1. Cross-sectional view of the ice chamber and surrounding tub. For illustration both the hard-bed and soft-bed configurations are shown. The tub is $1.15 \mathrm{~m}$ in diameter.

or soft beds, sensitive control of ice and bed temperature, observation of ice deformation and ice-bed separation, unlimited slip displacement driven at either a controlled rate or basal drag, application of steady stress normal to the bed, uninhibited movement of ice normal to the bed (contraction or dilation), suppression of longitudinal stress gradients, control of basal water pressure and simple convenient removal of ice for analysis after experiments.

Two styles of rotary shear devices, capable of unlimited slip displacement and without undesirable longitudinal edge effects, could potentially meet these criteria: (1) Couette-type devices in which one wall of the specimen chamber rotates and the plane of slip is usually oriented vertically (Meyssonnier, 1983); and (2) ring-shear devices in which the roof or base of the specimen chamber rotates and the slip plane is oriented horizontally (Iverson and others, 1997). The latter style was chosen because the slip plane is oriented properly with respect to gravity, which is important in studying some subglacial processes in which body forces are relevant, even over small length scales (e.g. till deformation). Ice and bed preparation prior to experiments and post-experimental analyses are also easier with the ring-shear design.

\section{Ice chamber and mechanical systems}

A ring of ice and an underlying rigid or soft bed are contained within a U-shaped annular aluminum chamber (Fig. 1). The inner surface of the outside wall of the ice chamber has a diameter of $0.90 \mathrm{~m}$ and the width of the annulus is $0.20 \mathrm{~m}$. The inside height of the ice chamber is $0.27 \mathrm{~m}$ and the nominal combined thickness of the ice and bed is $0.24 \mathrm{~m}$, with the bed accounting for $10-25 \%$ of this thickness. The plan-view dimensions of the ice chamber are limited by the need to apply realistically large stresses while keeping forces sufficiently small to be supported by a loading frame that fits in an existing cold room. The chamber height allows ice thickness to be roughly an order of magnitude greater than amplitudes of bed obstacles. The ratio of ice-chamber width to outside diameter minimizes the variation in slip velocity across the chamber width, while keeping the chamber width comparable to the ice thickness. The inside surfaces of the walls of the chamber are polished smooth, whereas their outside surfaces are wrapped in polyethylene closed-cell insulation. In the outside walls of the ice chamber there are four quartz-glass windows that allow video cameras to look into the chamber slightly above the level of the bed surface; these windows are located at $90^{\circ}$ intervals around the outer wall, with two windows at a level appropriate for experiments with hard beds and two higher windows appropriate for experiments with thicker soft beds (Figs 1 and 2). The ice chamber is mounted within a plastic tub (Figs 1 and 2) $(1.15 \mathrm{~m}$ in diameter and $0.53 \mathrm{~m}$ deep) that is part of the temperature-control system discussed hereinafter. Both the chamber and tub are mounted to a gusseted aluminum base plate (Fig. 2).

Rotation of a platen that grips the top of the ice ring slides it over the bed (Figs 1 and 2). This platen, $0.1 \mathrm{~m}$ thick and made of a strong plastic called Delrin, fits into the open top of the ice chamber, and radiating square teeth $(10 \mathrm{~mm})$ on the bottom of the platen couple it to the upper surface of the ice ring (Fig. 2). Delrin has a low thermal conductivity, which both isolates the ice ring from temperature fluctuations above the ice chamber and inhibits regelation of ice past the teeth. The teeth are spaced sufficiently closely that the platen roughness is significantly larger than chosen bed roughnesses, so that sliding will be focused at the bed rather than at the platen. In addition to sliding over the bed, the ice ring also slides along the smooth walls of the ice chamber. A large o-ring around the perimeter of the inner wall near its top and a second larger o-ring around the outside of the platen seal it against the ice-chamber walls (Fig. 1). Four drain holes extend from the base of the platen to the top of a gusseted aluminum plate that holds the platen (Fig. 1), where valves allow water or air to be released from the top of the ice chamber if necessary.

The platen, which hangs from a fixed composite aluminum and steel cross-member called the yoke (Fig. 2), is rotated either at a constant speed or under a controlled torque by a central shaft, thereby allowing experiments in which either slip velocity or drag can be controlled. The shaft is turned by two electric motors (Fig. 2), each with a small gearbox, a larger right-angle gear reducer (Fig. 2) and worm screw. The two worm screws turn a single worm gear on the shaft. The motors and gearboxes are mounted on opposite sides of the yoke, which contains the drive shaft and worm gear at its center. The total gear reduction is $2.3 \times 10^{6}$, enabling platen speeds at the ice-chamber center line from 29 to $2100 \mathrm{~m} \mathrm{a}^{-1}$. Ice speeds at the inside wall of the ice chamber are about $44 \%$ smaller than those at the outside wall. In experiments in which drag is regulated, the motors are servo-controlled with torque sensors on their 


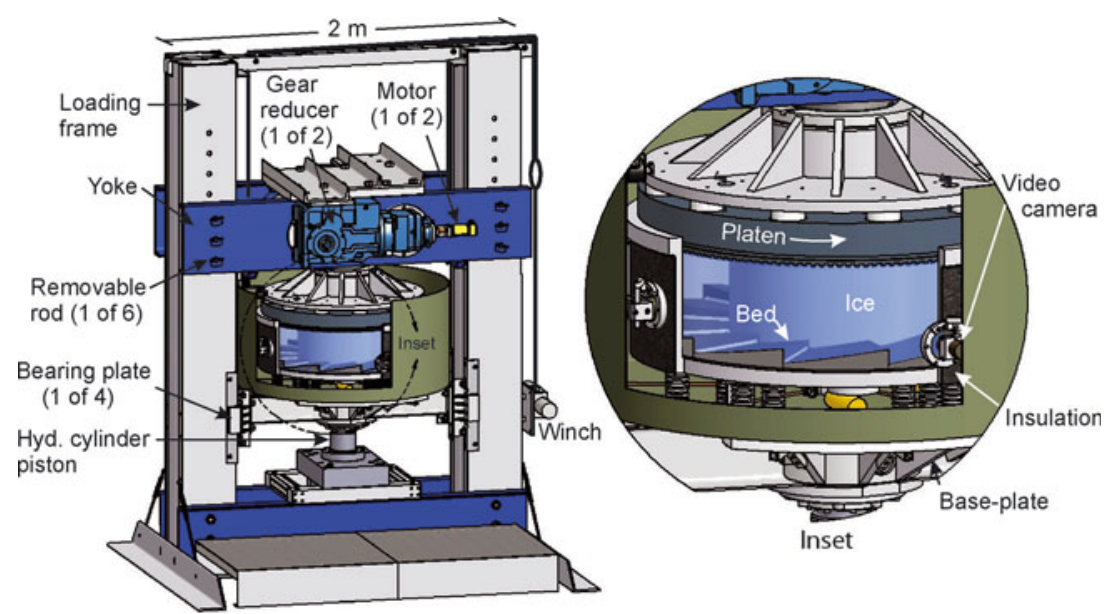

Fig. 2. Ring-shear device with a cutaway view of the ice chamber and stepped bed. External plumbing and wiring are not shown. Also not shown are the two heating/cooling circulators and the pump and control unit for the hydraulic press, all of which reside outside the cold room.

drive shafts so that platen speed is varied to keep drag close to a specified value (drag per unit bed area $<400 \mathrm{kPa}$ ).

A vertical stress, normal to the sliding direction, is applied to the ice ring with a 200 ton hydraulic press (Fig. 2). The ice chamber and surrounding tub are mounted on a base plate that rests on the press (Fig. 2). The press therefore pushes upward on the base plate and hence also on the ice ring; this force is resisted by the platen and bearings in the yoke. Although the press can exert stresses on the ice of up to about $4000 \mathrm{kPa}$, the platen and yoke were designed - on the basis of finite-element modeling of their internal stresses and elastic displacements - to safely support stresses up to $2000 \mathrm{kPa}$. This concession kept the device sufficiently small to fit in an existing cold room and was justified because effective stresses on the bed, rather than total stresses, govern most subglacial processes of interest. An essential capability of the hydraulic press is that it holds the vertical stress on the ice ring close to a specified value, while also allowing expansion or contraction of the ice chamber during sliding. The necessary servo-control is accomplished with a controller outside the cold room, which contains a pump and solenoid valves that either reduce or add hydraulic fluid pressure to the cylinder when its pressure drifts too far from the specified value. This system keeps normal stress essentially steady, with variability not exceeding 3\%. The upward reach of the cylinder's piston is $0.15 \mathrm{~m}$.

Both shear and normal forces during experiments are ultimately supported by a rigid loading frame (Fig. 2). This frame consists of two vertical columns, $2.86 \mathrm{~m}$ tall, connected at their bases by two lengths of heavy steel channel upon which the hydraulic press is mounted. To keep the columns as light and rigid as possible, they each consist of a circular aluminum tube $(0.35 \mathrm{~m}$ in diameter $)$ welded to external aluminum plates to yield a rectangular crosssection. The yoke, which holds the motors, gearing, bearings and underlying platen, can be moved up or down along the outsides of the two columns with a motor-driven winch and cables (Fig. 2). Importantly, the yoke can be fixed at various elevations with removable rods $(25.4 \mathrm{~mm}$ in diameter and $0.69 \mathrm{~m}$ long) that slide through holes in the yoke and columns. These rods - three through each column - allow the yoke to be positioned either immediately above the ice chamber during experiments (Fig. 2) or $\sim 0.9 \mathrm{~m}$ above the chamber between experiments when access to it is required.
During an experiment, the rods transfer the upward force on the yoke to the columns. The columns also support the torque on the ice chamber and base plate that results from drag associated with sliding; the columns are captive between steel bearing plates (Fig. 2) that extend from the base plate and keep it and the overlying ice chamber from rotating during sliding. Plastic bearing pads on the steel plates allow the base plate to slide smoothly up or down along the columns as the hydraulic cylinder piston extends or retracts in response to volume changes within the ice chamber.

\section{Temperature-control system}

Precise temperature control is necessary, particularly for experiments with temperate ice: the ice ring must be kept steadily and uniformly at the pressure-melting temperature but with sufficiently slow melting to allow experiments with durations of up to several months. Temperature variations within cold rooms (typically $\sim 1^{\circ} \mathrm{C}$ ) are too large and their thermostat settings are too coarse to adjust heat flow to the ice with the necessary precision.

Thus, although during experiments the cold room is set at $0^{\circ} \mathrm{C}$, so that it cycles from $-1^{\circ} \mathrm{C}$ to $0^{\circ} \mathrm{C}$, the ice chamber is submerged in a glycol/water mixture that has its temperature controlled with an $18 \mathrm{~L}$ heating/cooling circulator (Lauda Proline, RP1840) which resides outside the cold room. This circulator both regulates the fluid temperature with a precision of $0.01^{\circ} \mathrm{C}$ and pumps the fluid to the tub that surrounds the ice chamber. The fluid enters the tub through a basal distributing manifold (Fig. 1; fluid and exterior plumbing not shown) and moves upward past the specimen chamber before leaving the tub through overflow valves on its outer walls. The ice chamber is mounted on legs (Fig. 1), so the fluid moves beneath the chamber, as well as upward along its sides. These steel legs, which provide the only efficient and hence undesirable heat pathways to the specimen chamber from the air of the cold room, each have fins that extend from a solid core to maximize heat exchange with the fluid (Fig. 1). The fluid level in the tub can be set sufficiently high that the fluid flows above the platen, or can be set lower so that the fluid extends only to the top of the outer walls (Fig. 1). The fluid bath's upper surface is open to the atmosphere, so backflow to the circulator is by gravity. A solenoid valve on the inflow port to the circulator ensures that the backflow and outflow fluid discharges of the 


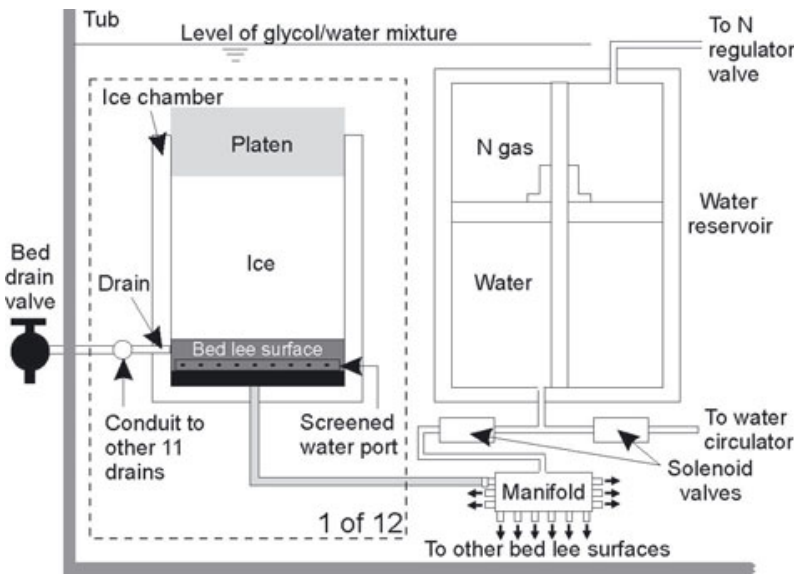

Fig. 3. Schematic of the hydraulic system for control of basal water pressure. Only one of 12 bed steps downstream from the manifold is shown.

circulator are equal, thereby keeping fluid levels in both the tub and circulator steady.

Temperature measurements at various locations in the fluid bath surrounding the ice chamber indicate that temperatures in the fluid are steady to within $0.01^{\circ} \mathrm{C}$ and do not vary spatially more than $0.024^{\circ} \mathrm{C}$. However, the temperature in the bath is consistently $\sim 0.2^{\circ} \mathrm{C}$ warmer than the regulated fluid temperature of the circulator, presumably as a result of frictional heat dissipation in the fluid as it flows through the external plumbing system to the tub. Insulation (10 $\mathrm{mm}$ thick polyethylene) (Fig. 2) around the perimeter of the ice chamber reduces heat flow to the ice from the circulating fluid, thereby optimizing the degree to which melt rates can be fine-tuned by changing the bath fluid temperature.

\section{Basal hydraulic system}

Water pressure at the bed can be regulated passively or actively. There are two passive approaches possible, analogous to the 'drained' and 'undrained' conditions of geotechnical soil testing (e.g. Clarke, 2005). In drained experiments, 12 uniformly spaced ports in the outer walls of the ice chamber and at approximately the elevation of the bed allow water to drain from the bed (Fig. 3). The ports drain to a single conduit that encircles the base of the ice chamber and connects to a valve at the outside of the tub. When this external valve is open and a pneumatically actuated solenoid valve is closed (left-hand solenoid in Fig. 3), the bed is 'drained' and water pressure does not deviate from atmospheric. In contrast, when the bed drain valve is closed, water cannot drain from the bed. Thus, if the volume of the ice chamber increases during sliding (e.g. due to formation of cavities on a rough rigid bed), water pressure less than atmospheric can develop. Alternatively, closure of such cavities could induce water pressures well above the atmospheric value.

Water pressure can also be controlled actively at the bed by opening the aforementioned solenoid valve that connects water at the bed with water in a cylindrical closed reservoir that resides at the center of the ice chamber (Figs 1 and 3). The reservoir is submerged in the circulating glycol/water mixture and thus this fluid regulates the temperature of water in the reservoir. An o-ring-sealed disk, which slides up and

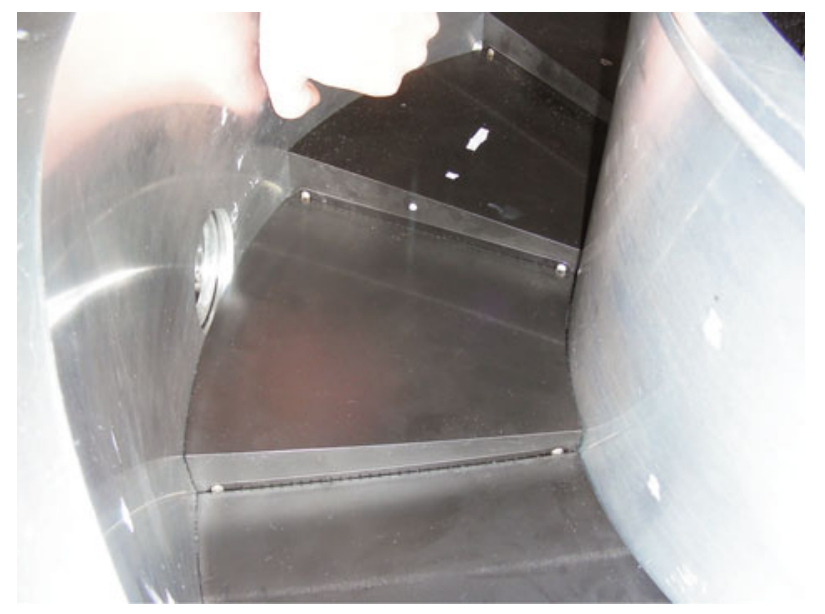

Fig. 4. Oblique view of a part of the ice chamber and stepped bed. Ice slides from top to bottom. A window for one of the video cameras is visible in the left-hand wall.

down within the reservoir on two vertical rods (only one shown in Figs 1 and 3), separates water below it from compressed nitrogen above it. A regulated nitrogen cylinder outside the cold room applies a downward pressure on the disk that is transferred to the water in the reservoir. The water-output conduit from the reservoir leads to the solenoid valve, and with a manifold the water is distributed through 12 separate conduits to uniformly spaced ports on the bottom of the ice chamber along its center line (Fig. 3). When the bed drain valve is closed, a change in ice chamber volume, due to for example cavity growth or closure at the bed, causes water to flow, respectively, toward or away from the bed and hence either out of or into the water reservoir, while pressure in the reservoir and at the bed is held steady.

The total volume of water in the system (both in the bed and reservoir) can be changed in two ways during experiments in which water pressure is controlled actively. Water can be drained directly from the bed and out of the system using the drain valve on the tub. Alternatively, if there is not sufficient water in the internal reservoir to supply the bed, water can be pumped to the reservoir with a second heating/cooling circulator outside the cold room by opening the right-hand solenoid valve in Figure 3. The circulator regulates the temperature of the added water to $0.01^{\circ} \mathrm{C}$. Water level in the internal reservoir is recorded by a small cable extensometer that tracks the vertical position of the disk that transfers the gas pressure to the water (Fig. 1).

\section{Beds}

Although either hard or soft beds can be used in the device (Fig. 1), initial experiments have been with a rigid bed comprised of tilted step-shaped bumps with vertical lee surfaces (Fig. 4). This is an appropriate idealization for glacier beds that consist of sub-horizontal layered sedimentary or metamorphic rocks (e.g. Hallet and Anderson, 1980) and may be a better idealization than a sinusoidal bed for most layered rocks. There are 12 identical steps in total, each with a wavelength at the ice-chamber center line of $0.183 \mathrm{~m}$. Each step segment is a separate piece that fits snugly into the base of the ice chamber. The bed is made of Delrin, with a thermal conductivity of $0.33 \mathrm{~W} \mathrm{~m}^{-1}{ }^{\circ} \mathrm{C}^{-1}$. This value is a factor of 7-15 smaller than those of common rocks and therefore regelation is insignificant, despite the small 
bump size. Inhibiting regelation is desirable because modern sliding models neglect it (e.g. Fowler, 1986; Schoof, 2005), a justifiable simplification because abrasion tends to smooth sub-decimeter bumps most susceptible to regelation.

The annular geometry of the ice chamber requires that either the step height or the slope of stoss surfaces must vary across the width of the chamber. Drag in models of hardbedded sliding is sensitive to slopes of stoss surfaces (Iken, 1981; Schoof, 2005), so slope was kept spatially uniform $\left(8.4^{\circ}\right)$. The uniform slope requires that steps increase linearly in height from 19.3 to $34.8 \mathrm{~mm}$ from the inside to the outside of the ice chamber (Fig. 1), with a step height of $27 \mathrm{~mm}$ at the chamber center line. This height is $\sim 11 \%$ of the overlying ice-ring thickness.

In experiments in which water pressure is controlled actively, water is conveyed to the base of each step segment through one of the 12 ports at the base of the ice chamber. A screened port across the width of each lee surface (Figs 1 and 4) connects water in conduits within each step segment to its lee surface. The 12 drains from the bed in the outer walls are located immediately below the crest of each step.

At least two other hard beds will be used. A bed with sinusoidal bumps similar in size to that of the stepped bed is being fabricated. Also, a flat smooth Delrin bed has been fabricated to study the magnitude of slip resistance during sliding that is unrelated to drag associated with bed roughness.

In experiments with soft beds, till (or another sediment of interest) will be spread in a layer of uniform thickness $(\sim 0.06 \mathrm{~m})$ at the base of the ice chamber (Fig. 1$)$. In this case, the 12 water-entry ports at the base of the ice chamber and the 12 drains in the outer walls will be screened to prevent till entry, but otherwise the water system will be unchanged from the hard-bed case. A complication with soft beds is that there will be significant friction between the till and the ice-chamber walls, unlike where melting ice contacts the walls. Based on our experience with another ring-shear device, this friction will not affect till deformation kinematics, except within a few centimeters of the walls (Iverson and others, 1997). However, the overall shear resistance of the bed will be larger than in the absence of wall friction, and unlike in our other device the shear traction supported by the walls cannot be measured separately. Fortunately, the effect of the walls is reduced by the large width-to-depth ratio of the bed $(\sim 3: 1)$ and the tendency for lateral stresses to be significantly smaller than vertical stresses in vertically loaded, confined granular materials (Lambe and Whitman, 1969).

\section{Measurements}

Temperature is measured at 44 locations in the bed and walls using glass bead thermistors. Of these, 14 are in four of the bed segments, arranged so that they are spaced uniformly about the ice chamber. Each thermistor, arranged in a full-bridge circuit, is calibrated in an ice-water bath with a high-precision reference thermistor. Standard errors of the calibrations are $0.0005-0.0040^{\circ} \mathrm{C}$. Actual measurement uncertainties are probably somewhat larger, but less than $\pm 0.01^{\circ} \mathrm{C}$.

The vertical stress normal to the ice ring and drag associated with sliding are measured with a load cell and torque sensor, respectively. The load cell is connected to the top of the piston of the hydraulic cylinder and pushes upward on the base plate that supports the ice chamber. The top of the torque sensor is mounted to the bottom of a thick aluminum plate that holds the worm gear. The bottom of the torque sensor is bolted to the gusseted aluminum plate (Fig. 1) which holds the platen that grips the ice ring. Thus, the sensor records the torque required to turn the platen. This torque results from slip resistance both at the bed and walls, but drag of temperate ice on the smooth walls is expected to be negligible.

Water pressure at the bed is measured with four vibratingwire piezometers positioned at $90^{\circ}$ intervals about the perimeter of the ice chamber (Fig. 1). These sensors, which reside in the glycol/water mixture, screw into the outer walls of the ice chamber, with each of their ports positioned where a cavity is expected, immediately down-flow from and below a bump crest.

Various displacements are recorded. The rotation of the platen is periodically measured manually and can also be tracked continuously with an encoder wheel that presses on the platen. The ice velocity within a few centimeters of the bed surface is measured with two video cameras (Fig. 2) by tracking the displacement of colored beads frozen into the ice ring during its construction. This ice velocity near the bed surface is less than the speed of the platen at the top of the ice ring. Relative displacements of beads in initially vertical columns allow vertical gradients in horizontal velocity to be determined. Although the video cameras can see only the lowest beads in these columns, the full displacement profile is visible after ice rings have been removed from the ice chamber. Importantly for studies of ice-bed separation, expansion and contraction of the ice chamber are measured with a linear variable displacement transducer (LVDT) that tracks the upward or downward motion of the piston on the hydraulic cylinder (Fig. 2). For example, as cavities grow or shrink at the bed surface, the piston and overlying ice chamber move downward or upward, respectively, allowing cavity volume changes to be determined.

\section{A FIRST EXPERIMENT WITH A STEPPED BED}

\section{Motivation}

Ice-bed separation caused by glacier sliding over a rough rigid bed has interested theoreticians for over half a century (e.g. Lliboutry, 1958) and has been a key element in interpreting results from numerous field studies (e.g. Kamb and others, 1985; Iken and Bindschadler, 1986; Hooke and others, 1989; Iken and Truffer, 1997; Anderson and others, 2004; Sugiyama and Gudmundsson, 2004; Harper and others, 2005, 2007; MacGregor and others, 2005; Bartholomaus and others, 2008). The process plays a central role in theories of subglacial hydrology (e.g. Walder, 1986; Schoof, 2010), glacier sliding (e.g. Iken, 1981; Fowler, 1986; Schoof, 2005) and surging (e.g. Kamb, 1987) and quarrying of subglacial bedrock (Iverson, 1991; Hallet, 1996). Despite this interest, there are no data that establish relationships between steady cavity size, bed geometry, sliding speed and effective pressure. Field studies are complicated by various factors that are poorly known, including the bedrock geometry, cavity size and local drag on the bed. Cavity growth and shrinkage are commonly estimated from glacier surface velocities but usually with the uncertain assumption that vertical strain rates in the glacier are uniform with depth (see Sugiyama and Gudmundsson, 2004, for an exception). 

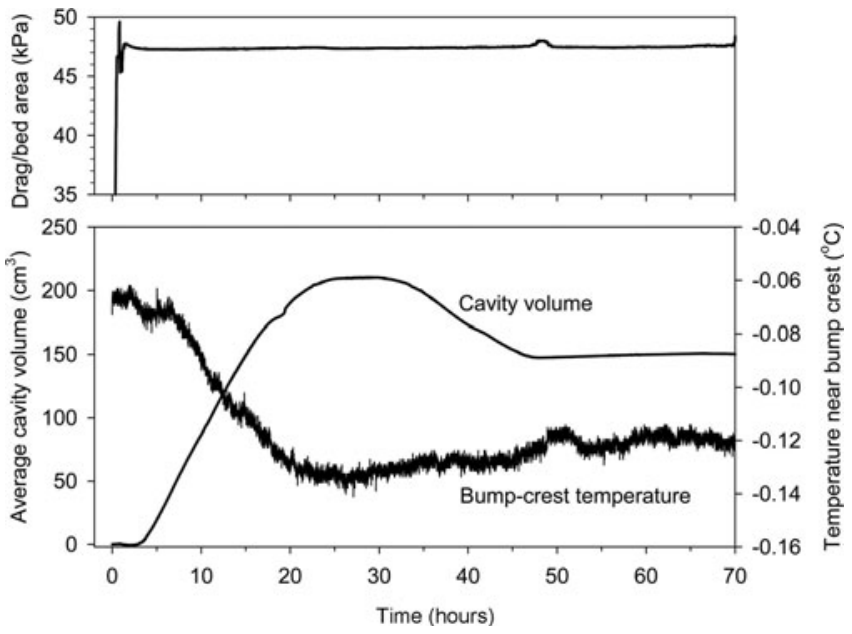

Fig. 5. Drag per unit bed area, average volume of cavities and temperature at the bed surface near a bump crest during the initial 70 hours of the experiment. The slip velocity was $29 \mathrm{~m} \mathrm{a}^{-1}$ at the ring center line.

Thus, the first experiment with the device was aimed at studying steady and transient ice-bed separation as a function of slip velocity and gathering ancillary data on basal drag and ice deformation. Slip velocity was controlled as an independent variable, and cavity size and drag were measured. For simplicity, the device was operated in its 'drained' mode, so valves were set to allow water to drain freely from the bed, with no attempt to regulate basal water pressure. Cavities at the bed were thus at atmospheric pressure.

\section{Procedure}

An ice ring was constructed by adding successive layers of deionized water, $10-15 \mathrm{~mm}$ thick, to the ice chamber. To promote a random crystal fabric, these layers were seeded with ice particles $(\sim 0.5-6.0 \mathrm{~mm})$ to nucleate crystals during freezing. Bead columns were frozen into the ice to act as displacement markers. After the ice ring was sufficiently thick, the yoke was fixed at its lowest position on the loading frame, so that the platen was $\sim 50 \mathrm{~mm}$ above the ice surface. A final water layer was added to the ice ring, which was then pushed upward into contact with the platen by raising the ice chamber and base plate with the hydraulic cylinder. Freezing of the water layer coupled the platen teeth to the ice ring. A vertical stress of $\sim 300 \mathrm{kPa}$ was applied to the ice ring, and over a period of 3 days the ice was brought to the pressure-melting temperature by increasing the temperature of the circulating glycol/water mixture incrementally. Temperatures at the surfaces of the bed and walls indicated approximately when the pressure-melting temperature was reached, as did contraction of the ice chamber indicative of melting at the ice-ring periphery, with drainage of water from the chamber. Melting at the interior of the ice ring lagged melting at its periphery, so a week was allowed to elapse before increasing the vertical stress on the ice to the operative value for slip: $1010 \mathrm{kPa}$. An abrupt reduction in temperature of the bed surface $\left(\sim 0.05^{\circ} \mathrm{C}\right)$ commensurate with the increase in pressure confirmed that the ice was at the pressure-melting temperature. The decrease in ice temperature required lowering the temperature of the glycol/water mixture to keep melt rates sufficiently small, as indicated by the rate of ice-chamber contraction (contraction rates $<100 \mathrm{~mm} \mathrm{a}^{-1}$ ).

Once contraction rate was small and steady, slip was initiated by rotating the platen at a steady rate. Slip caused dilation of the ice chamber due to ice-bed separation. Eventually, dilation transitioned back to a steady rate of contraction, indicating that ice was melting at a steady rate and cavities on the bed had attained a steady size. Steady cavity sizes and drags on the bed were attained at slip velocities of 29,87 and $290 \mathrm{ma}^{-1}$, and repeated at the highest speed at the end of the experiment (all velocities and displacements reported are at the plan-view center line of the ice ring). Twice during the experiment, sliding was stopped to test sensors, and during these periods there was rapid contraction of the ice chamber but at a steadily decreasing rate, indicative of cavity closure.

After sliding was stopped at the end of the experiment, the vertical stress was immediately removed from the ice ring. The ice chamber was lowered with the hydraulic jack, and the platen and yoke were winched upward and pinned at their highest position on the loading frame. Then, using the winch (Fig. 2), a harness and ice screws set into the surface of the ice ring, the ring $(\sim 80 \mathrm{~kg})$ was lifted out of the chamber and swung gently onto a table. There the ice was photographed, marker-bead locations were measured and the topography of the base of the ice ring was measured with a point gauge and jig to determine cavity sizes and shapes. Parts of the ice ring were thin-sectioned, along horizontal planes and away from its edges, for fabric measurements with a universal stage.

\section{Results}

Ice separated from vertical lee surfaces at all slip velocities and, after an increase in slip velocity, cavity volume oscillated before attaining a steady value. In Figure 5, time series of drag, cavity volume and bed surface temperature are plotted for the initial and smallest slip velocity chosen, $29 \mathrm{~m} \mathrm{a}^{-1}$. Upon turning on the motors that drive rotation of the upper platen, there was rapid accumulation of drag (per unit bed area) to $\sim 46 \mathrm{kPa}$, followed by a period of unsteady drag that became steady at $47.3 \mathrm{kPa}$ about 2.5 hours after platen rotation commenced. During this period, there was $\sim 8 \mathrm{~mm}$ of platen displacement, which included both elastic shear flexure of the ice and slip at the bed surface as indicated by video observations. As drag became steady, cavities began to develop on the bed, as indicated by dilation of the ice chamber. Cavity volume increased for the next 25 hours ( $\sim 83 \mathrm{~mm}$ of platen displacement), reaching a maximum of $\sim 210 \mathrm{~cm}^{3}$ per cavity. As cavity volume increased, bed surface temperature $10 \mathrm{~mm}$ upstream from step edges decreased from the pre-sliding temperature of $\sim-0.07^{\circ} \mathrm{C}$, commensurate with the ice pressure of $1010 \mathrm{kPa}$ (considering a melting depression with pressure of $7.4 \times 10^{-5 \circ} \mathrm{C} \mathrm{kPa}^{-1}$ ), to a minimum temperature of $\sim-0.13^{\circ} \mathrm{C}$, indicative of local pressure on the bed equal to $\sim 1750 \mathrm{kPa}$. After reaching a maximum value, the cavity volume then decreased about $30 \%$ before increasing slightly again and eventually attaining a steady value of $\sim 155 \mathrm{~cm}^{3}$ (Fig. 5). Bed surface temperature increased about $0.015^{\circ} \mathrm{C}$ in response to the decrease in cavity volume from its maximum value. Attainment of steady-state cavity size required $\sim 65$ hours of slip and a slip displacement of $\sim 215 \mathrm{~mm}$. With the exception of a minor $1 \mathrm{kPa}$ excursion at about hour 48, drag remained steady, despite the large variation in cavity volume. 


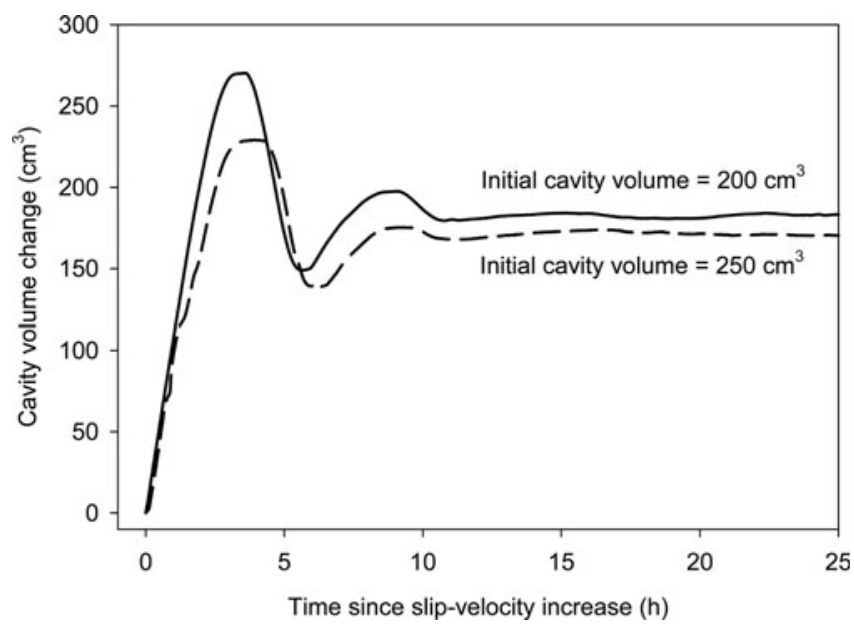

Fig. 6. Change in cavity volume due to an increment in slip velocity of $290 \mathrm{~m} \mathrm{a}^{-1}$ at the ice-ring center line, for two initial cavities of similar size.

When prompted by larger increases in slip velocity, the non-monotonic increase to a steady cavity size, like that of Figure 5, always had the form of a damped oscillation (Fig. 6). Twice when slip velocity was increased to $290 \mathrm{ma}^{-1}$, starting with initial cavities of comparable volume (200 and $250 \mathrm{~cm}^{3}$ ), the approach to a new larger steady size consisted of similar oscillations that decreased in amplitude with displacement. In both cases a slip displacement of $\sim 650 \mathrm{~mm}$ was required to reach a steady cavity size, and drag was steady as cavities changed their volume.

Although cavity volume could be determined from the LVDT that tracked dilation of the ice chamber, the geometry of individual cavities could be determined only by profiling directly the sole of the ice ring after it was removed from the ice chamber; video images obtained during the experiment captured only portions of cavities. The average steady shape of cavities, developed along the ice-ring center line at the final slip velocity of $290 \mathrm{~m} \mathrm{a}^{-1}$, is shown in Figure 7 , with error bars depicting $\pm 1 \mathrm{SD}$. Cavities spanned about $74 \%$ of stoss surfaces at this slip velocity. Cavity roofs began at step edges and were mildly concave-down, with little variability among cavities. The arcuate profile of cavity roofs was interrupted within $\sim 10 \mathrm{~mm}$ of the point of ice reconnection with the bed, where cavities became slightly enlarged. Profiles measured on either side of the ice-ring center line indicated that cavity volume was symmetrically disposed about the center line, so that center-line longitudinal cross sections provided an accurate measure of average cavity volume.

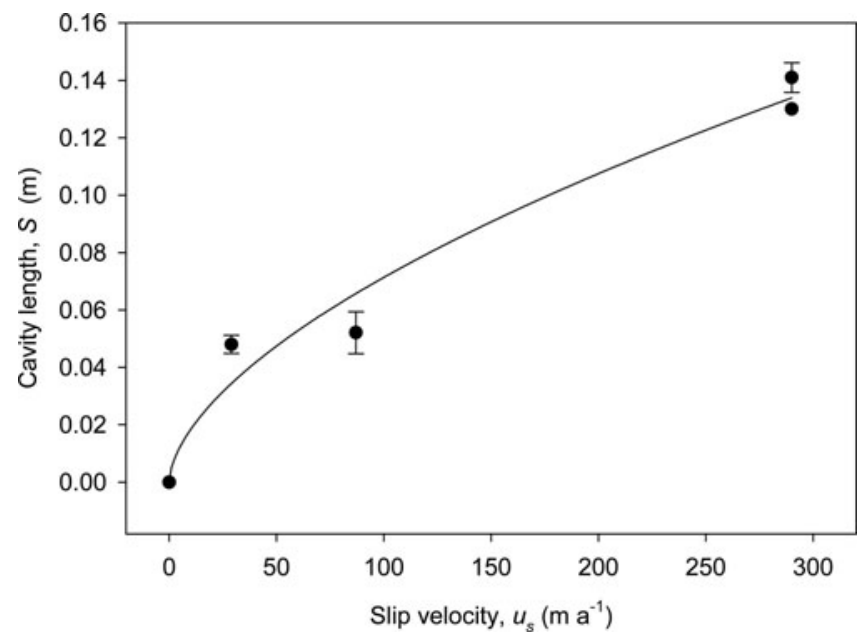

Fig. 8. Steady average cavity length as a function of slip velocity. Error bars reflect the range of possible melt rates, which affect calculated cavity volumes used to infer cavity length.

There have been various theoretical efforts to estimate lengths of steady cavities in the lee of bed steps as a function of slip velocity (e.g. Walder, 1986; Kamb, 1987), so this relationship from the experiment was explored by estimating steady-state cavity lengths from measured cavity volumes at the various slip velocities chosen. A straight line was fitted to points measured along the average cavity roof profile at the end of the experiment (Fig. 7). The ratio of actual cavity cross-sectional area to that for the linear roof was used to estimate cavity lengths from known volumes of steady cavities from earlier in the experiment, when the extent of roof curvature was unknown. Cavity length as a function of slip velocity is shown in Figure 8. A power-law fit to the data, noting that there was no ice-bed separation at zero slip velocity, indicates that cavity length depended on slip velocity raised to a power of 0.59 .

A relationship between steady slip velocity and drag, the relationship that has been the focal point of most sliding models, is shown in Figure 9. There was no systematic dependence of drag on slip velocity, despite the wide range of cavity sizes indicated in Figure 8 and a slip velocity variation through two orders of magnitude. Drag varied $<2 \%$.

Post-experimental analysis of the ice ring provided information about ice deformation during sliding. Deformation, as indicated by marker beads, was focused in the lower half of the ice ring (Fig. 10), consistent with video observations of deformation early in the experiment (Fig. 11). Marker-bed deflection near the bases of bead columns indicated shear strains of $>30$. Interestingly, the lowest

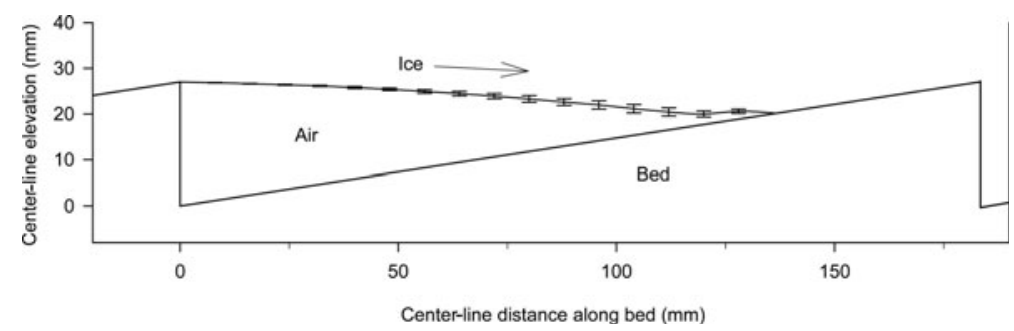

Fig. 7. Steady average cavity geometry at the ice-ring center line at the end of the experiment. Error bars indicate \pm 1 SD. The slip velocity was $290 \mathrm{ma}^{-1}$. 


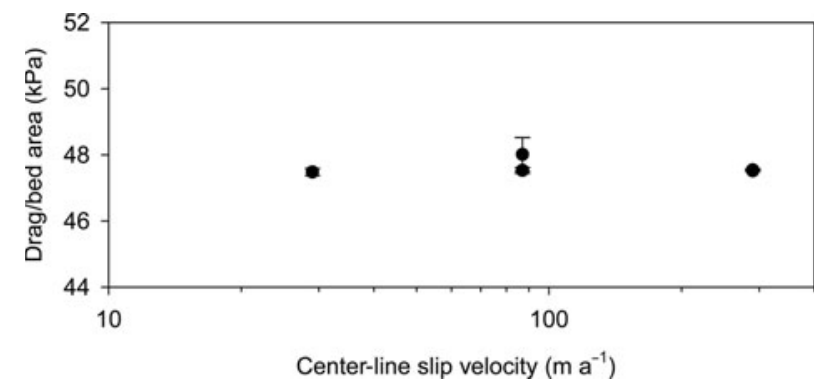

Fig. 9. Steady drag per unit bed area at the three slip velocities of the experiment. Error bars span $1 \mathrm{SD}$ of the stress variability.

marker beads, originally within $2 \mathrm{~mm}$ of the bed, were $\sim 30 \mathrm{~mm}$ above the sole of the ice ring at the end of the experiment (Fig. 10). Ice within $\sim 40 \mathrm{~mm}$ of the bed and subject to the highest strain was transparent due to loss of air bubbles there during ice deformation. Bubble concentration above this zone was roughly correlated with strain magnitude. $c$-axis fabrics measured at three depths in the lower half of the ice ring did not vary significantly and consisted of steeply plunging multiple clusters (Fig. 12). The mean grain size of this ice was $6.3 \pm 3.5 \mathrm{~mm}$ ( $\pm 1 \mathrm{SD})$. In contrast, ice near the top of the ring, which was subject to near-zero deformation, had close to a random fabric (Fig. 12), with a significantly larger mean grain size of $11.4 \pm 6.2 \mathrm{~mm}$.

\section{Discussion}

These data provide an opportunity to evaluate approximate models of steady step cavities on a rigid bed (Fig. 13). In most such models, the borehole-closure analysis of Nye (1953) has been adapted, so that the rate of closure of leeward cavities, $u_{\mathrm{c}}$ is approximately

$$
u_{\mathrm{C}}=L\left(\frac{P_{e}}{n B}\right)^{n}
$$

where $P_{\mathrm{e}}$ is the effective pressure, the difference between the ice-overburden and cavity water pressure, $n$ and $B\left(\mathrm{~Pa} \mathrm{~s}^{1 / 3}\right)$ are the ice flow-law parameters as defined by Glen (1955) and $L$ is a length chosen as an approximate surrogate for the borehole radius. Walder (1986, equation 8 ) chose $L$ to be the step height, which led to a linear dependence of cavity length on slip velocity. Schoof (2010) made the same assumption in estimating cavity cross-sectional area. This linear dependence is not supported by our data (Fig. 8) and implies that larger cavities resulting from higher slip velocities will have closure rates equal to those of smaller cavities, which is counterintuitive. An alternative is to consider $L$ to be equal to

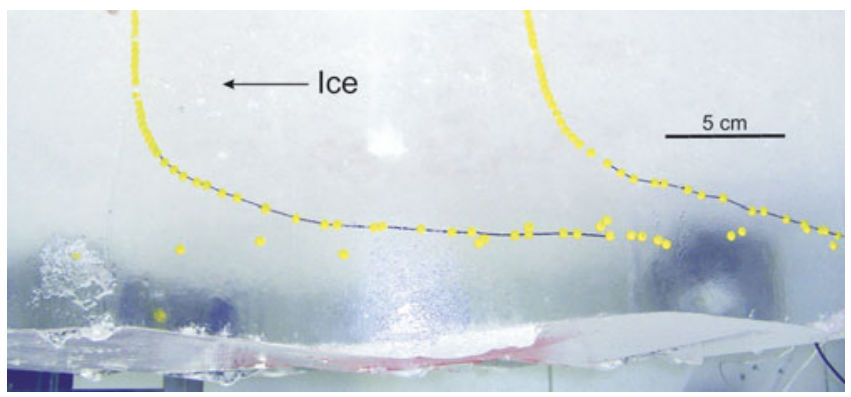

Fig. 10. Initially vertical columns of glass beads at the end of the experiment, viewed through the outer edge of the ice ring. The scale is approximate due to the curvature of the ring.

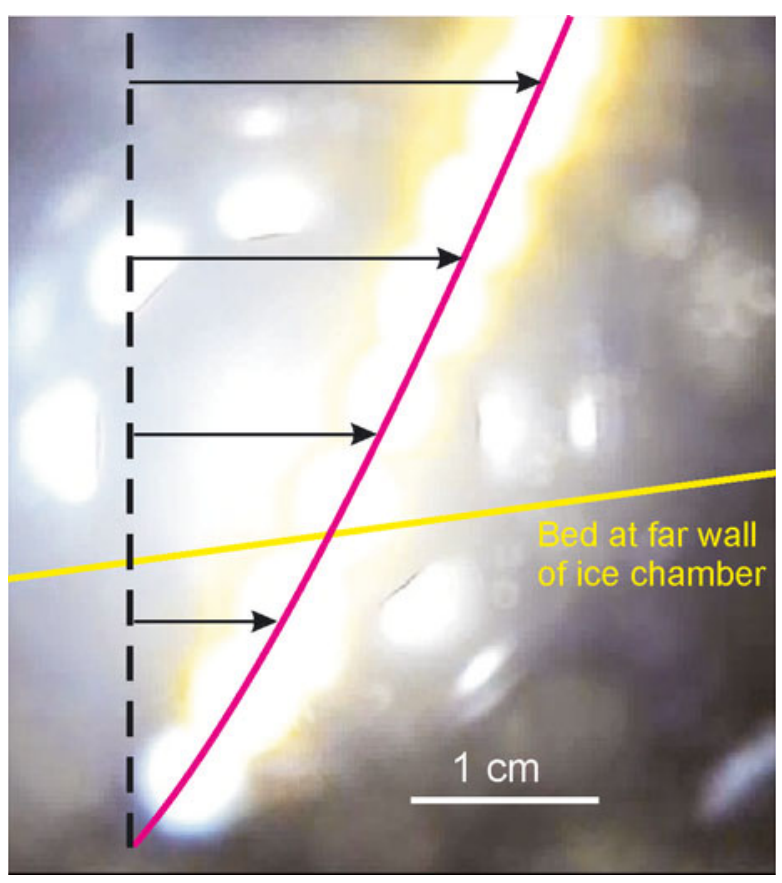

Fig. 11. Video image of an initially vertical column of beads in ice that has sheared and shortened vertically while climbing over a step on the bed.

the cavity length, $S$ (Fig. 13). Adopting this approximation but otherwise following the derivation of Walder (1986) yields the steady-state value of $S$ :

$$
S=\left(u_{\mathrm{s}} h\right)^{1 / 2}\left(\frac{n B}{P_{\mathrm{e}}}\right)^{1 / 2}
$$

where $u_{\mathrm{s}}$ is the slip velocity, $h$ is the step height, and melting of the cavity roof is assumed to be negligible, as was true for the air-filled cavities of the experiment. This expression is essentially the same as that presented in the sliding analysis of Humphrey (1987). Kamb (1987) approached the stepcavity problem differently by obtaining an exact solution for the case of $\mathrm{S} \gg \mathrm{h}$ and linear-viscous ice:

$$
S=4\left(\frac{\eta u_{\mathrm{s}} h}{\pi P_{\mathrm{e}}}\right)^{1 / 2}
$$

where $\eta$ is the ice viscosity and roof melting is negligible. He

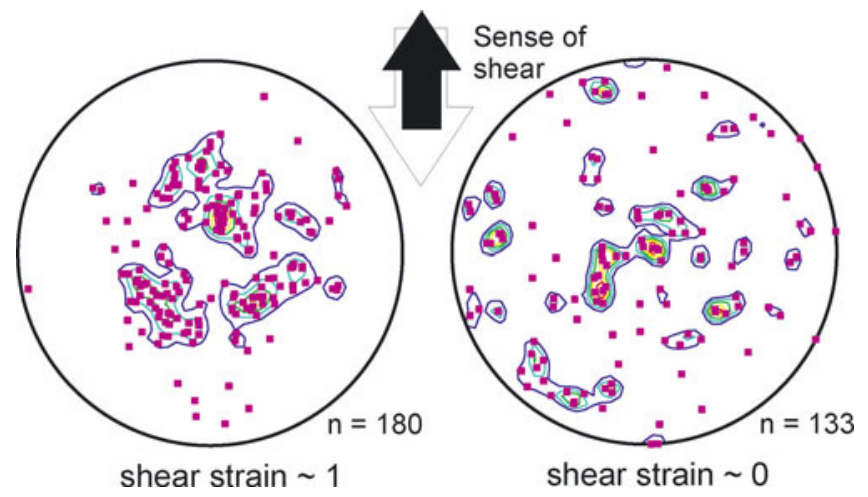

Fig. 12. Lower-hemisphere stereonets of ice $c$-axis orientations ( $1 \%$ area contouring with $2 \sigma$ intervals) measured in horizontal thin sections collected at about $0.07 \mathrm{~m}$ above step crests (shear strain $\sim 1$ ) and near the top of the ice ring (shear strain $\sim 0$ ). 


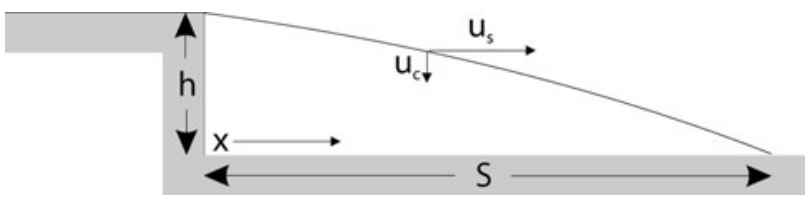

Fig. 13. Step-cavity parameters as defined in model approximations.

suggested adapting this expression approximately for the case of nonlinear ice by noting that $\eta=\eta_{\mathrm{R}}\left(\tau_{\mathrm{R}} / P_{\mathrm{e}}\right)^{n-1}$, where $\eta_{\mathrm{R}}$ is the effective viscosity at a reference shear stress $\tau_{R}$. Relating these two quantities with Glen's flow law indicates that

$$
\eta=\frac{B^{n}}{2 P_{e}^{n-1}},
$$

which if substituted into Equation (2) yields

$$
S=4\left(\frac{u_{\mathrm{s}} h}{2 \pi}\right)^{1 / 2}\left(\frac{B}{P_{\mathrm{e}}}\right)^{n / 2} .
$$

This relationship for $S$, alluded to but not presented by Kamb (1987), has the same form as Equation (2) obtained using Nye (1953), with the two expressions differing by only a numerical factor. For $n=3$, the approximation for $S$ based on Kamb's model is a factor of $\sim 3.3$ smaller than that based on Nye's borehole-closure theory.

Before comparing these model approximations with observations of cavity length in the experiment, geometrical differences between the models and experiments need to be acknowledged. In the models steps are isolated, whereas in the experiment there were adjacent steps and cavities. In the model based on Kamb (1987), $S \gg h$, whereas in the experiment, $1.8 h<S<5.2 h$. Sliding is directed parallel to stoss surfaces in the models; in the experiment stoss surfaces were inclined at $\sim 8^{\circ}$ to the far-field sliding direction. In the models ice thickness is assumed to be infinitely large, whereas the thickness of the ice ring was approximately nine times the step height. The models also, of course, do not account for the curvilinear geometry of the ice chamber. Initial efforts are underway to eliminate these geometrical differences by using methods described by Gagliardini and others (2007) to numerically model step cavities in the domain of the ice chamber. In the meantime, however, analytical approximations (Equations (2) and (5)) merit comparison with our data despite these geometrical differences and the conceptual simplifications of the models.

Both approximations indicate that cavity length will depend on $u_{\mathrm{s}}{ }^{1 / 2}$, which is close to the $u_{\mathrm{s}}{ }^{0.59}$ dependence of the experiment (Fig. 8). This exponent of 0.59 could indicate that the appropriate value for $L$ in Equation (1) lies between $S$ and $h$, which yield the theoretical exponents of 0.5 and 1.0, respectively, although that conclusion is uncertain until more data are collected. Further comparison of theoretical and experimental cavity sizes requires that values of $n$ and $B$ be chosen for the experimental ice. Choosing $n=3$ is justified because deviatoric stresses in the vicinity of cavities under an effective pressure of $1010 \mathrm{kPa}$ are likely too large to warrant smaller values $(n<2)$ typical of deformation that is rate-limited by grain boundary migration (Montagnat and Duval, 2000) or sliding (Goldsby and Kohlstedt, 2001). The value of $B$, however, can be chosen with little confidence and thus we consider a wide range of
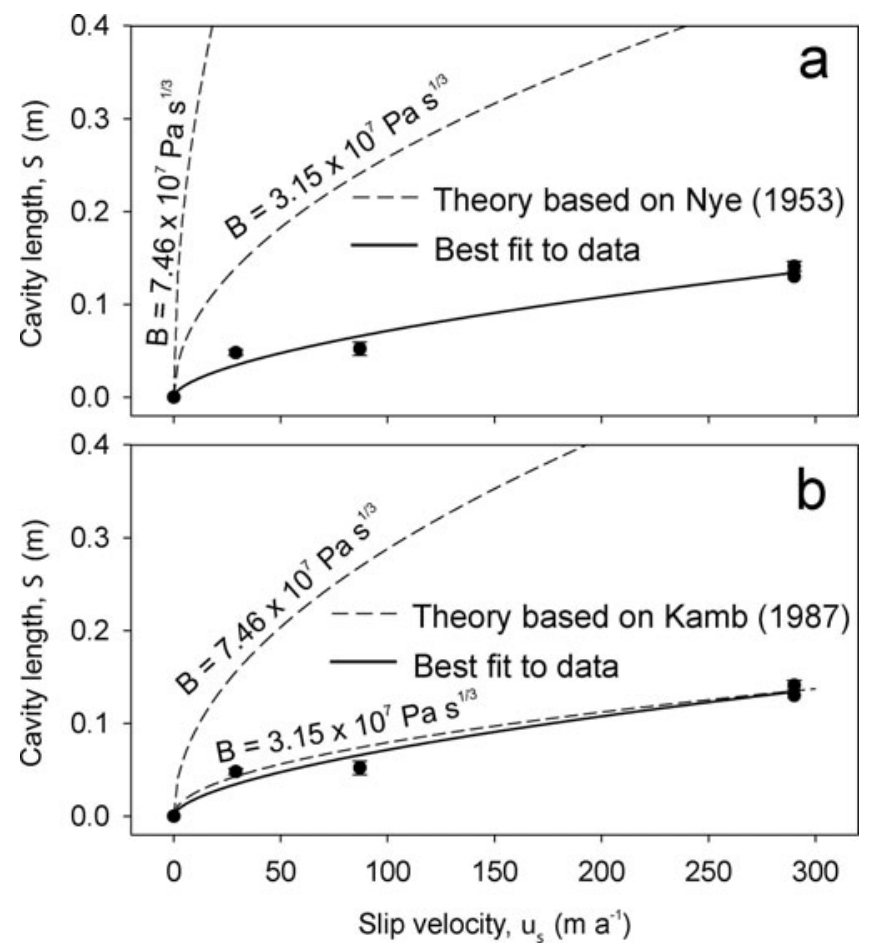

Fig. 14. Experimental cavity length as a function of slip velocity compared with model approximations that follow from (a) Nye's (1953) borehole-closure theory and (b) Kamb's step-cavity model. Model results are computed using limiting values of $B$ as described in the text.

observed values: $3.2-7.5 \times 10^{7} \mathrm{Pas}^{1 / 3}$. The lower bound is the mean of values obtained in situ for basal ice of Engabreen, Norway (Kohler, 1993; Cohen, 2000); the upper bound is the value for clean temperate ice suggested by Cuffey and Paterson (2010). With these flow-law parameters, the formulation based on Nye borehole closure (Equation (2)) significantly overestimates cavity length (Fig. 14a). The Kamb model, as adjusted herein (Equation (5)), provides a better estimation but agrees with the data only if the experimental ice is assumed to have been very soft (Fig. 14b).

Although such soft ice cannot be ruled out, the tendency for both models to overestimate cavity length, $S$, is more likely a result of a model shortcoming or of the experiment violating model assumptions. A notable example of the latter is that cavities were not isolated in the experiment and covered up to $74 \%$ of the bed: intervening ice was, therefore, likely subjected to deviatoric stresses higher than model values, with resultant higher closure rates and smaller values of $S$. Also, owing to drag associated with the inclination of the experimental steps, slip velocity at the bed was $\sim 30 \%$ less than the platen velocity, as indicated by video observations of bead velocities. However, reducing experimental slip velocities of Figure 14 to account for this difference would reduce model overestimates only slightly. Also noteworthy is that a different handling of Nye's (1953) borehole-closure theory may have resulted in an improved model approximation. For example, if $L$ in Equation (1) had been set equal to the radius of curvature of the cavity roof rather than to $S$, which is smaller, closure rates would have been larger, with smaller predicted values of $S$. Unfortunately, the radius of curvature of cavity roofs was known only at the end of the experiment and thus for only one of 
the points in Figure 8. Additional experiments, each terminated at a different slip velocity, would allow this approach to be tested.

During transient cavity adjustment to increases in slip velocity, cavities grew but non-monotonically (Fig. 5), with damped volume oscillations (Fig. 6). These oscillations have not been described previously or predicted theoretically and their cause is uncertain. A working hypothesis is that they develop due to interplay between transient cavity shape and closure rates, so that these variables oscillate together until a steady cavity volume and shape commensurate with slip velocity is eventually achieved.

Steady shapes of cavities were comparable with those computed by Kamb (1987), except very near where ice reconnected with the bed (Fig. 7). The anomalous enlargement of cavities there was likely a scale effect resulting from meltwater held there by surface tension. Heat conduction from the bed and through that water likely melted cavity roofs, unlike upstream where roofs were insulated by air in cavities.

Despite cavity growth after slip-velocity increments and wide ranges of steady-state cavity sizes, drag was steady at $\sim 47.5 \mathrm{kPa}$ (Figs 5 and 9). The exception was during the first 2.5 hours of slip when ice separated from the vertical lee surfaces of the bed (Fig. 5). Once this initial separation was complete, drag remained unchanged throughout the experiment. As cavities oscillated in size, the local stress on the bed clearly changed, as indicated by temperature changes of portions of the bed surface in contact with ice (Fig. 5), but these stress changes had no effect on drag. Note that although some of the measured drag was likely exerted by the walls of the device as the ice ring rotated, this drag must have been minor because the walls were smooth and thermistors there indicated that ice was at the pressuremelting temperature. Thus, the measured drag was mostly a consequence of the bed shear stress, which was clearly independent of slip velocity and cavity size.

Ice at the bed, therefore, was apparently in the state of limit equilibrium first described by Iken (1981) and alluded to by Schoof (2005) as Iken's bound: the limiting value of shear stress that a given bed geometry can support at a particular effective pressure. The bound depends on the steepness of stoss surfaces. Only if they are sufficiently steep to be normal to the sliding direction does the upper bound not exist, such that static stress equilibrium can be sustained unconditionally. For the case of the experimental steps, which had uniformly sloping stoss surfaces, differences in cavity size had no effect on the bed slope resisting ice flow in zones of ice-bed contact, so changes in cavity size and slip velocity had no effect on basal drag. In contrast, for a sinusoidal bed the mean slopes of zones of ice-bed contact would be progressively smaller for progressively larger cavities that extend beyond the midpoints of stoss surfaces, causing decreasing drag at larger slip velocities (e.g. Schoof, 2005; Gagliardini and others, 2007). Efforts to construct a sinusoidal bed are underway.

Iken's bound has the form of the Coulomb friction criterion $\tau_{\mathrm{b}}=P_{\mathrm{e}} \tan \beta$, where $\beta$ is the uniform slope of stoss surfaces (e.g. Schoof, 2005). In the experiment $P_{e}=1010 \mathrm{kPa}$, equal to the vertical stress on the ice ring because cavities were air-filled and $\beta=8.4^{\circ}$. Thus, if the curvilinear geometry of the bed is neglected, $\tau_{b}=149 \mathrm{kPa}$, a factor of $\sim 3$ larger than the measured value. This discrepancy prompted us to apply an independently measured torque to the platen (Figs 1 and 2) to test the fidelity of the torque-sensor record used to determine drag during sliding. With a wire-rope/turnbuckle/ load-cell assembly, a range of torques was applied symmetrically to the platen perimeter. This exercise reproduced the torque-sensor calibration to within $2 \%$. Thus, the difference between the measured and predicted value of Iken's bound was not due to measurement error. Moreover, the curvilinear geometry of the bed cannot likely account for the size of the discrepancy. To date, it is unexplained, but we hope that its source will become evident as additional data are collected with different bed geometries and we begin to numerically model flow in the domain of the ice chamber.

Marker beads indicate that deformation associated with sliding occurred near the bed (Fig. 11), with no resolvable deformation or slip of ice near the upper platen. As hoped, the high density, low thermal conductivity and rectilinear shape of the teeth on the platen suppressed relative motion between it and the ice ring. Although the reason for the significant upward deflection of beads from the bed is uncertain, it may have resulted from non-uniform opening and closing of cavities during the experiment, such that ice transiently and repeatedly flowed beneath adjacent ice that contained beads. There was no ice textural evidence of water freezing to the sole of the ice ring.

The multiple-cluster $c$-axis fabrics that developed in ice deformed near the base of the ring (Fig. 12) have been observed in previous experiments (Kamb, 1972; Duval, 1981) but are poorly understood. However, there seems to be consensus that such fabrics are indicative of recrystallization of ice at or near its pressure-melting temperature under simple shear and compression normal to the plane of shear (Hooke, 2005; Cuffey and Paterson, 2010). Such fabrics have been produced in laboratory ice by repeated compression with intervening periods of annealing (Huang and others, 1985). Ice in the ring likely experienced similar stress fluctuations as it climbed steps, causing vertical compression, followed by periods of unloading as it traversed cavity roofs. Regardless of the reason for multiple-cluster fabrics, their prominence in sheared ice of temperate glaciers (Kamb, 1959; Vallon and others, 1976) and sometimes near the bases of ice sheets (Gow and Williamson, 1976) indicates that the synthetic ice of the experiment developed fabric, at shear strains $<1.0$ (Fig. 12), comparable with that of glacier ice. Therefore, use of synthetic ice in future experiments is justifiable, particularly given the potential difficulty of collecting, transporting and trimming the large volume of glacier ice that would be necessary for use in the device.

\section{CONCLUSIONS}

Results of the first experiment demonstrate some of the device's capabilities. A large ice ring, kept at the pressuremelting temperature by circulating a temperature-regulated fluid around the ice chamber that contains the ring, can be rotated across a rough horizontal rigid bed over a wide range of glacially relevant speeds. Dilation and contraction of the ice chamber, under a vertical near-constant stress $(<3 \%$ variation), allow the extent of ice-bed separation to be recorded continuously. The low thermal conductivity of the Delrin bed suppresses regelation, so that ice moves past bumps primarily through deformation - the focus of recent models. Ice is sheared to very high strains $(>30)$ and develops a multiple-maximum fabric at low strains $(<1.0)$ like that commonly observed in the sheared ice of temperate glaciers. 
Exploiting the other capabilities of the device in future experiments will involve various degrees of difficulty. For example, experiments with a flat bed, to assess drag in the absence of bed roughness, and with a sinusoidal rigid bed, will not involve additional technical challenges. Similarly, replacing the rigid bed with a soft bed will be straightforward. Experiments at a controlled drag, rather than at a controlled slip velocity, will likely be harder to conduct, but short tests at specified drags have, to date, been successful. Most challenging will be experiments with either hard or soft beds in which basal water pressure is controlled independently. Whether the ice chamber will be able to seal water under a pressure approaching the largest vertical ice stresses possible $(2000 \mathrm{kPa})$ for the duration of an experiment ( $>1$ month) will be uncertain until such tests are conducted.

Results from the first experiment bear on ice-bed separation during sliding, although these conclusions will likely be refined as more experiments are conducted:

1. In response to increases in slip velocity, cavity volume increased non-monotonically, displaying damped oscillations as a steady volume was approached.

2. Steady cavity length depended on $u_{\mathrm{s}}^{0.59}$. This result is in general agreement with the square-root dependence that follows from two independent approximate models based on the surge theory of Kamb (1987) and on Nye's (1953) borehole-closure theory (e.g. Humphrey, 1987). This result is in poorer agreement with the linear dependence used in some linked-cavity hydrological models (Walder, 1986; Schoof, 2010). Whether there is a square-root or a linear dependence is a consequence of whether, respectively, cavity length or step height is chosen as the length scale in the equation for closure rate.

3. The approximation based on Kamb (1987) provided a better estimate of steady cavity length than that derived from Nye's (1953) theory. Both approximations, however, underestimated closure rates and overestimated cavity size.

4. Once ice had completely separated from lee surfaces, drag was constant and independent of cavity size and slip velocity. This result is anticipated for bed steps with planar, uniformly sloping stoss surfaces and consistent with sliding models that acknowledge an upper bound to drag on the bed (e.g. Iken, 1981; Schoof, 2005).

Clearly, a high priority for future analysis of more extensive data will be to evaluate effects of scale on ice-bed separation by scaling the relevant flow equations and thereby defining appropriate dimensionless variables. A high priority for future experiments will be to study effects of steady and transient water pressure in cavities on beds of different geometries. Theoretical studies (e.g. Gagliardini and others, 2007) indicate that the form of the sliding rule that might emerge from these studies will be sensitive to bed shape.

The device will be useful for studying other subglacial processes, bearing in mind that the goal of such experiments will not be to simulate processes fully, which is seldom possible or arguably even desirable, but to judiciously simplify systems in order to understand them better. This is essentially the same reductionist viewpoint that has guided pioneering theoretical treatments of subglacial processes, such as those focused on hard-bedded sliding (e.g. Weertman, 1957; Lliboutry, 1968). Additional processes targeted for study with the device might include slip of debris-laden ice over a rigid bed (Cohen and others, 2005), glacial abrasion (Hallet, 1979), subglacial till deformation and ploughing (Iverson and others, 2007), stick-slip sliding (Bindschadler and others, 2003), till strengthening by water withdrawal associated with basal freezing (Tulaczyk and others, 2000), regelation infiltration during slip (Rempel, 2008), lodgment-till deposition (Boulton, 1975) and sliding and sediment entrainment by cold-based glaciers (Cuffey and others, 2000). Although the device will not be a panacea for study of these processes, for some problems we expect it to provide a better vehicle for definitive hypothesis tests than either field or modeling studies.

\section{ACKNOWLEDGEMENTS}

We thank T. Herrman and D. Jones of the US Department of Energy Ames Laboratory for their help designing and fabricating the device. Construction and use of the device were made possible by grants from the US National Science Foundation: ANT-0618747 and EAR-1023586.

\section{REFERENCES}

Anderson, R.S. and 6 others. 2004. Strong feedbacks between hydrology and sliding of a small alpine glacier. J. Geophys. Res., 109(F3), F03005. (10.1029/2004JF000120.)

Bartholomaus, T.C., R.S. Anderson and S.P. Anderson. 2008. Response of glacier basal motion to transient water storage. Nature Geosci., 1(1), 33-37.

Bindschadler, R.A., M.A. King, R.B. Alley, S. Anandakrishnan and L. Padman. 2003. Tidally controlled stick-slip discharge of a West Antarctic ice stream. Science, 301(5636), 1087-1089.

Boulton, G.S. 1975. Processes and patterns of subglacial sedimentation: a theoretical approach. In Wright, A.E. and F. Moseley, eds. Ice ages: ancient and modern. Liverpool, Seel House Press, 7-42. (Geology Journal Special Issue 6.)

Boulton, G.S. 1996. Theory of glacial erosion, transport and deposition as a consequence of subglacial sediment deformation. J. Glaciol., 42(140), 43-62.

Brepson, R. 1979. Simulated glacier sliding over an obstacle. J. Glaciol., 23(89), 143-156.

Budd, W.F., P.L. Keage and N.A. Blundy. 1979. Empirical studies of ice sliding. J. Glaciol., 23(89), 157-170.

Clark, P.U., R.B. Alley and D. Pollard. 1999. Northern Hemisphere ice-sheet influences on global climate change. Science, 286(5442), 1104-1111.

Clarke, G.K.C. 2005. Subglacial processes. Annu. Rev. Earth Planet. Sci., 33, 247-276.

Cohen, D. 2000. Rheology of ice at the bed of Engabreen, Norway. J. Glaciol., 46(155), 611-621.

Cohen, D., N. Iverson, T. Hooyer, U. Fischer, M. Jackson and P. Moore. 2005. Debris-bed friction of hard-bedded glaciers. J. Geophys. Res., 110(F2), F02007. (10.1029/2004JF000228.)

Cuffey, K.M. and W.S.B. Paterson. 2010. The physics of glaciers. Fourth edition. Oxford, Butterworth-Heinemann.

Cuffey, K.M. and 8 others. 2000. Entrainment at cold glacier beds. Geology, 28(4), 351-354.

Dieterich, J.H. 1979. Modeling of rock friction 1. Experimental results and constitutive equations. J. Geophys. Res., 84(B5), 2161-2168.

Dreimanis, A. and P. Gibbard. 2005. Stratigraphy and sedimentation of the stratotype sections of the Catfish Creek Drift Formation between Bradtville and Plum Point, north shore, Lake Erie, southwestern Ontario, Canada. Boreas, 34(2), 101-122.

Duval, P. 1981. Creep and fabrics of polycrystalline ice under shear and compression. J. Glaciol., 27(95), 129-140. 
Egholm, D.L., S.B. Nielsen, V.K. Pedersen and J.-E. Lesemann. 2009. Glacial effects limiting mountain height. Nature, 460(7257), 884-887.

Fowler, A.C. 1986. A sliding law for glaciers of constant viscosity in the presence of subglacial cavitation. Proc. R. Soc. London, Ser. A, 407(1832), 147-170.

Gagliardini, O., D. Cohen, P. Råback and T. Zwinger. 2007. Finiteelement modeling of subglacial cavities and related friction law. J. Geophys. Res., 112(F2), F02027. (10.1029/2006JF000576.)

Glen, J.W. 1955. The creep of polycrystalline ice. Proc. R. Soc. London, Ser. A, 228(1175), 519-538.

Goldsby, D.L. and D.L. Kohlstedt. 2001. Superplastic deformation of ice: experimental observations. J. Geophys. Res., 106(B6), 11,017-11,030.

Gow, A.J. and T. Williamson. 1976. Rheological implications of the internal structure and crystal fabrics of the West Antarctic ice sheet as revealed by deep core drilling at Byrd Station. Geol. Soc. Am. Bull., 87(12), 1665-1677.

Hallet, B. 1979. A theoretical model of glacial abrasion. J. Glaciol., 23(89), 39-50.

Hallet, B. 1981. Glacial abrasion and sliding: their dependence on the debris concentration in basal ice. Ann. Glaciol., 2, 23-28.

Hallet, B. 1996. Glacial quarrying: a simple theoretical model. Ann. Glaciol., 22, 1-8.

Hallet, B. and R.S. Anderson. 1980. Detailed glacial geomorphology of a proglacial bedrock area at Castleguard Glacier, Alberta, Canada. Z. Gletscherkd. Glazialgeol., 16(2), 171-184.

Harper, J.T., N.F. Humphrey, W.T. Pfeffer, T. Fudge and S. O'Neel. 2005. Evolution of subglacial water pressure along a glacier's length. Ann. Glaciol., 40, 31-36.

Harper, J.T., N.F. Humphrey, W.T. Pfeffer and B. Lazar. 2007. Two modes of accelerated glacier sliding related to water. Geophys. Res. Lett., 34(12), L12503. (10.1029/2007GL030233.)

Hooke, R.LeB. 2005. Principles of glacier mechanics. Second edition. Cambridge, etc., Cambridge University Press.

Hooke, R.LeB. and N.R. Iverson. 1985. Experimental study of ice flow around a bump: comparison with theory. Geogr. Ann., 67A(3-4), 187-197.

Hooke, R.LeB., P. Calla, P. Holmlund, M. Nilsson and A. Stroeven. 1989. A 3 year record of seasonal variations in surface velocity, Storglaciären, Sweden. J. Glaciol., 35(120), 235-247.

Huang, M., M. Ohtomo and G. Wakahama. 1985. Transition in preferred orientation of polycrystalline ice from repeated recrystallization. Ann. Glaciol., 6, 263-264.

Humphrey, N.F. 1987. Coupling between water pressure and basal sliding in a linked-cavity hydraulic system. IAHS Publ. 170 (Symposium at Vancouver 1987-The Physical Basis of Ice Sheet Modelling), 105-119.

Iken, A. 1981. The effect of the subglacial water pressure on the sliding velocity of a glacier in an idealized numerical model. J. Glaciol., 27(97), 407-421.

Iken, A. and R.A. Bindschadler. 1986. Combined measurements of subglacial water pressure and surface velocity of Findelengletscher, Switzerland: conclusions about drainage system and sliding mechanism. J. Glaciol., 32(110), 101-119.

Iken, A. and M. Truffer. 1997. The relationship between subglacial water pressure and velocity of Findelengletscher, Switzerland, during its advance and retreat. J. Glaciol., 43(144), 328-338.

Iverson, N.R. 1991. Potential effects of subglacial water-pressure fluctuations on quarrying. J. Glaciol., 37(125), 27-36.

Iverson, N.R. 1993. Regelation of ice through debris at glacier beds: implications for sediment transport. Geology, 21(6), 559-562.

Iverson, N.R., R.W. Baker and T.S. Hooyer. 1997. A ring-shear device for the study of till deformation: tests on tills with contrasting clay contents. Quat. Sci. Rev., 16(9), 1057-1066.
Iverson, N.R. and 7 others. 2007. Soft-bed experiments beneath Engabreen, Norway: regelation infiltration, basal slip, and bed deformation. J. Glaciol., 53(182), 323-340.

Kamb, W.B. 1959. Ice petrofabric observations from Blue Glacier, Washington, in relation to theory and experiment. J. Geophys. Res., 64(11), 1891-1909.

Kamb, B. 1972. Experimental recrystallization of ice under stress. In Heard, H.C., I.Y. Borg, N.L. Carter and C.B. Raleigh, eds. Flow and fracture of rocks. Washington, DC, American Geophysical Union, 211-241. (Geophysical Monograph 16.)

Kamb, B. 1987. Glacier surge mechanism based on linked cavity configuration of the basal water conduit system. J. Geophys. Res., 92(B9), 9083-9100.

Kamb, B. and 7 others. 1985. Glacier surge mechanism: 19821983 surge of Variegated Glacier, Alaska. Science, 227(4686), 469-479.

Kohler, J. 1993. Engabreen subglacial observatory: field report, March. NVE Tech. Rep. 11-1993.

Lambe, T.W. and R.V. Whitman. 1969. Soil mechanics. New York, etc., John Wiley and Sons.

Lliboutry, L. 1958. Contribution à la théorie du frottement du glacier sur son lit. C. R. Hebd. Séances Acad. Sci., 247(3), 318-320.

Lliboutry, L. 1968. General theory of subglacial cavitation and sliding of temperate glaciers. J. Glaciol., 7(49), 21-58.

MacGregor, K.R., C.A. Riihimaki and R.S. Anderson. 2005. Spatial and temporal evolution of rapid basal sliding on Bench Glacier, Alaska, USA. J. Glaciol., 51(172), 49-63.

Marone, C. 1998. Laboratory-derived friction laws and their application to seismic faulting. Annu. Rev. Earth Planet. Sci., 26, 643-696.

Meyssonnier, J. 1983. Ecoulement de la glace sur un lit de forme simple: expérience, modélisation, paramétrisation du frottement. (Thèse de Doctorat d'État, Université de Grenoble.)

Montagnat, M. and P. Duval. 2000. Rate controlling processes in the creep of polar ice: influence of grain boundary migration associated with recrystallization. Earth Planet. Sci. Lett., 183(1-2), 179-186.

Nye, J.F. 1953. The flow law of ice from measurements in glacier tunnels, laboratory experiments and the Jungfraufirn borehole experiment. Proc. R. Soc. London, Ser. A, 219(1139), 477-489.

Rempel, A.W. 2008. A theory for ice-till interactions and sediment entrainment beneath glaciers. J. Geophys. Res., 113(F1), F01013. (10.1029/2007JF000870.)

Scholz, C.H. 2002. The mechanics of earthquakes and faulting. Second edition. Cambridge, etc., Cambridge University Press.

Schoof, C. 2005. The effect of cavitation on glacier sliding. Proc. $R$. Soc. London, Ser. A, 461(2055), 609-627.

Schoof, C. 2010. Ice-sheet acceleration driven by melt supply variability. Nature, 468(7325), 803-806.

Segall, P., A.M. Rubin, A.M. Bradley and J.R. Rice. 2010. Dilatant strengthening as a mechanism for slow slip events. J. Geophys. Res., 115(B12), B12305. (10.1029/2010JB007449.)

Sugiyama, S. and G.H. Gudmundsson. 2004. Short-term variations in glacier flow controlled by subglacial water pressure at Lauteraargletscher, Bernese Alps, Switzerland. J. Glaciol., 50(170), 353-362.

Tulaczyk, S.M., B. Kamb and H.F. Engelhardt. 2000. Basal mechanics of Ice Stream B, West Antarctica. II. Undrainedplastic-bed model. J. Geophys. Res., 105(B1), 483-494.

Vallon, M., J.R. Petit and B. Fabre. 1976. Study of an ice core to the bedrock in the accumulation zone of an Alpine glacier. J. Glaciol., 17(75), 13-28.

Walder, J.S. 1986. Hydraulics of subglacial cavities. J. Glaciol., 32(112), 439-445.

Weertman, J. 1957. On the sliding of glaciers. J. Glaciol., 3(21), $33-38$. 